\title{
Diabetic Retinopathy, Visual Impairment, and the Risk of Six-Year Death: A Cohort Study of a Rural Population in China
}

\author{
Kai Cao ${ }^{\mathrm{a}}$ Bingsong Wang ${ }^{\mathrm{b}}$ David S. Friedman ${ }^{\mathrm{c}}$ Jie Hao ${ }^{\mathrm{a}}$ Ye Zhang $^{\mathrm{b}}$ \\ Ailian $\mathrm{Hu}^{\mathrm{a}}$ Ningli Wang ${ }^{\mathrm{a}, \mathrm{b}}$ The Handan Eye Study Group \\ aBeijing Institute of Ophthalmology, Beijing Tongren Hospital, Capital Medical University, Beijing, China; ${ }^{b}$ Beijing

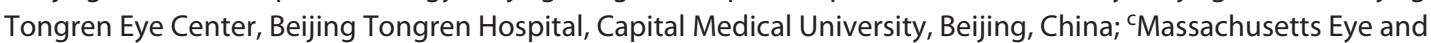 \\ Ear Glaucoma Center of Excellence, Harvard Medical School, Boston, MA, USA
}

\section{Keywords}

Diabetic retinopathy $\cdot$ Risk - Death $\cdot$ Cohort study .

Epidemiology

\begin{abstract}
Purpose: The aim of this study was to explore the association between diabetic retinopathy (DR) and the risk of 6-year death, as well as the association between visual impairment (VI) and the risk of 6-year death in a rural Chinese population of age $\geq 30$ years. Methods: This was a population-based cohort study. In 2006-2007, 6,830 subjects aged $\geq 30$ years were recruited from 13 villages in Northern China through clustered randomization. In 2012-2013, a 6-year follow-up was further done. Six different proportional hazards models, with different confounders adjusted, were used to explore the association between baseline DR and risk of death. $\boldsymbol{R e}$ sults: 5,570 subjects were included in this study by our inclusion and exclusion criteria. Four hundred and ten (7.36\%) subjects died by follow-up. The median ages of the dead subjects and survived subjects were 67 (interquartile range [IQR]: 58-72) years and 52 (IQR: 42-58) years $(Z=21.979, p<$
\end{abstract}

Bingsong Wang and Kai Cao contributed equally to this study and should be considered co-first authors.

karger@karger.com

(c) 2020 S. Karger AG, Basel

www.karger.com/ore

Karger $\stackrel{\text { ! }}{=}$
0.001). Male accounted for 62.20 and $44.92 \%$ among the dead and survived subjects $\left(x^{2}=45.591, p<0.001\right)$. Besides, compared with those survived, the dead were found to be with lower education $\left(x^{2}=109.981, p<0.001\right)$, lower marriage rate $\left(x^{2}=101.341, p<0.001\right)$, lower income $\left(x^{2}=\right.$ $123.763, p<0.001)$, higher proportion of smoking $\left(x^{2}=8.869\right.$, $p=0.003)$, higher systolic blood pressure $(Z=10.411, p<$ $0.001)$, lower body mass index $(Z=-3.302, p=0.001)$, larger spherical equivalent error $(Z=4.248, p<0.001)$, lower intraocular pressure $(Z=-4.912, p<0.001)$, smaller anterior chamber depth $(Z=-9.186, p<0.001)$, larger length thickness $(Z=11.069, p<0.001)$, higher fast blood glucose level $(Z=5.650, p<0.001)$, higher total cholesterols $(Z=2.015, p$ $=0.044)$, higher low-density lipoprotein $(Z=2.024, p=0.043)$, and higher proportion of drug usage $\left(x^{2}=56.108, p<0.001\right)$. Besides, the dead subjects were more likely to be with VI, glaucoma, cataract, age-related macular degeneration, diabetes, and DR. Hundred and forty-eight subjects were diagnosed with DR at baseline, and 33 (22.30\%) of them were dead before follow-up. By adjusting all relative confounders in a proportional hazards model, DR was found to be a risk factor of 6-year death, the hazard ratio was 1.739 (95\% confidence intervals: 1.080, 2.803). Another 5 different statistical models with different confounders adjusted also revealed a statistically significant association between DR and 6-year

Correspondence to:

Ningli Wang,wningli@vip.163.com 
death. The association between VI and 6-year death was not statistically significant. Conclusions: DR increased the risk of 6-year death in a rural Chinese population aged $\geq 30$ years, while VI did not.

(c) 2020 S. Karger AG, Basel

\section{Introduction}

Diabetic retinopathy (DR), a microvascular complication from diabetes, is the leading cause of visual impairment (VI) in the working-age population and the elderly [1]. A systematic review and meta-analysis involving 3,983,541 participants estimated that DR ranked the fifth leading cause of moderate to severe VI globally. By 2020, 3.2 million people all over the world would be with moderate to severe VI caused by DR [2].

Epidemiological evidence revealed that DR increased the risk of mortality in diabetes patients [3, 4]. Garofolo and coworkers [3] recruited 774 type 1 diabetes patients; after a follow-up of 10.8 years, 54 (7.0\%) were dead. The mortality was merely $2.7 \%$ among 452 subjects without DR, while among DR patients, the mortality raised to $13.0 \%$. Sabanayagam and coworkers [4] recruited 2,964 diabetic patients aged $40-80$ years in Singapore; over a follow-up of 8.8 years, they found that the risk of all-cause mortality was significantly increased in DR patients, with a HR of 1.54 compared with subjects without DR. Few population-based studies, such as the Singapore Malay Eye Study [5] carried out in Singapore and the Central Australian Ocular Health Study [6] carried out in Austria, reported similar findings on the association between DR and mortality.

However, evidence from population-based studies is still limited. China has one-fifth of the world's population, and over half of them live in the rural area. The Chinese people have their special lifestyle, the life expectancy, health-care services, and risk factors for mortality might be different from other nations. In this study, we aimed to explore the association between DR and the risk of 6-year death, as well as VI and the risk of 6-year death, in a cohort of rural Chinese population aged $\geq 30$ years.

\section{Methods}

\section{Study Design}

This was a population-based cohort study in Handan city, Hebei Province, China (The Handan Eye Study [HES]). Briefly, the baseline study was done in 2006-2007, and 6,830 subjects of age $\geq 30$ years were recruited from 13 villages by a clustered-randomization sampling technique. Six years later, in 2012-2013, a follow-up study was further done. The methodology, study design, examinations, questionnaires, and disease definitions were described in detail elsewhere $[7,8]$.

\section{Inclusion and Exclusion Criteria}

In this article, subjects without readable baseline eye fundus were excluded since the diagnosis of DR was dependent on eye fundus. Besides, subjects without fast blood glucose (FBG) without record of history of diabetics or anti-glycemic drug use were excluded. Participants whose were lost to follow-up were excluded either.

\section{Measurements and Definitions}

At baseline, participants underwent a standardized interview and completed an ophthalmologic and physical examination. At the detailed interview, participant demographics, socioeconomic status (including income and education level), and lifestyle risk factors (including smoking and drinking habit) were collected. Also fasting venous blood samples were collected for analysis of blood glucose and blood lipid levels (including total cholesterol, total triglycerides, high-density lipoprotein, and low-density lipoprotein). Physical examination included measurement of blood pressure. The ophthalmologic examination included measurement of visual acuity (VA), intraocular pressure (IOP), anterior and posterior ocular segment examinations, visual field testing and fundus, and optic disc photography.

VA was measured using the LogMAR number chart under standardized lighting conditions at a distance of $4 \mathrm{~m}$. If no number was read at the 4-m distance, the participants were moved to a distance of $3 \mathrm{~m}, 2 \mathrm{~m}$, or $1 \mathrm{~m}$, consecutively. If no number was identified, VA was assessed as counting fingers, hand motions, light perception, or no light perception. According to World Health Organization criteria, a patient with VA $<20 / 60$ would be defined as VI. In this article, presenting VA of the better eye was used for VI definition and analysis, best-corrected VA was not included in the analysis due to collinearity consideration [9].

Glaucoma was defined using the definition developed by the International Society for Geographical and Epidemiological Ophthalmology [10]. Cataract was assessed by ophthalmologists with slit-lamp microscopy examination after pupil dilation using the Lens Opacification Classification System III [11]. The presence of DR was assessed from the retinal fundus images using the Early Treatment of Diabetic Retinopathy Study adaptation of the modified Airlie House classification system [12].

\section{Assessment of Death}

In 2012-2013, the participants took part in the follow-up study, and participants who had died were registered and recorded by village doctors; the researchers visited each village to double check through relatives or friends.

\section{Statistical Analysis}

Only examinations of the right eye of the following parameters were included in the analysis: spherical equivalent error, IOP, anterior chamber depth (ACD), length thickness, and axial length. The Shapiro-Wilk test was used to check whether continuous variables were normally distributed or not. The median value and interquartile range (IQR) were used for basic statistical description of non-normally distributed continuous data; frequency 
and percentage were used for basic statistical description for categorical data. The Wilcoxon rank-sum test was used to make comparison of non-normally distributed continuous data between the survived and dead subjects, and $\chi^{2}$ test was used to make comparison of categorical data between the survived and dead subjects. Six different proportional hazards models, adjusting for age, gender, and/or other confounders, were used to explore the association between baseline DR and the 6-year death. Odds ratio (OR), with its' 95\% confidence interval (CI), was used to estimate the effect size of the association. All missing data were imputed by a Markov chain Monte Carlo method. The significance level was set to be $<0.05,2$-tailed. All analyses were conducted using an open source R program (version 4.0.0).

\section{Results}

Among 6,830 subjects recruited at baseline, 5,570 were included in this study, and another 1,260 were excluded due to lack of eye fundus, lack of FBG measurement, lack of record of history of diabetics or anti-glycemic drug use, or due to loss to follow-up. The median age of all included subjects was $53.00(43.00-60.00)$ years. There were 2,573 (accounting for $46.19 \%$ ) male participants. Eight hundred and seventy (15.62\%) subjects were of illiteracy, 2,843 (51.04\%) finished primary school, and only 1,857 (33.34\%) finished middle school or higher education. Five thousand and sixty-one $(90.86 \%)$ subjects were currently married, and another 509 (9.14\%) were single, widow, or divorced. Thousand nine hundred and thirty-three (34.70\%) subjects had no income in the last year before follow-up, 2,423 (43.50\%) earned $<5,000 \mathrm{RMB}$ in last year, and only $1,214(21.80 \%)$ earned 5,000 RMB or more in last year. Thousand seven hundred and sixty-six (31.71\%) subjects reported a smoking history, and 1,185 (21.27\%) subjects reported a drinking history. The baseline characteristics of all included participants are shown in Table 1.

A total of $410(7.36 \%)$ subjects were died by the time of follow-up. Specifically, among 148 baseline DR patients, $33(22.30 \%)$ died by the time of follow-up. We further compared other information between the dead subjects and the survived subjects (Table 2); it turned out that the median ages of the dead and survived subjects were 67 (IQR: 58-72) years and 52 (IQR: 42-58) years, and the dead were older than those who survived $(Z=21.979, p<$ 0.001 ). Male subjects accounted for 62.20 and $44.92 \%$ among the dead and survived subjects, and more male subjects died than female subjects $\left(\chi^{2}=45.591, p<0.001\right)$. The proportion of illiteracy in the dead group (32.20\%) was statistically higher than that of the survived group $(14.30 \%)\left(\chi^{2}=109.981, p<0.001\right)$. About $77.07 \%$ dead
Table 1. Characteristics of included subjects

\begin{tabular}{ll}
\hline Variables & Value \\
\hline $\begin{array}{l}\text { Age } \\
\text { Gender, } n \text { (\%) }\end{array}$ & $53.00(43.00-60.00)$ \\
$\quad$ Male & $2,573(46.19)$ \\
$\quad$ Female & $2,997(53.81)$ \\
Education, $n$ (\%) & \\
$\quad$ Illiteracy & $870(15.62)$ \\
$\quad$ Primary school & $2,843(51.04)$ \\
$\quad$ Middle school or higher & $1,857(33.34)$ \\
Marriage, $n$ (\%) & \\
$\quad$ Single/divorced/widow & $509(9.14)$ \\
$\quad$ Married & $5,061(90.86)$ \\
Income in the last year, $n$ (\%) & \\
$\quad$ No income & $1,933(34.70)$ \\
$\quad 1-5,000$ (RMB) & $2,423(43.50)$ \\
$\quad>5,000$ (RMB) & $1,214(21.80)$ \\
Smoke, $n$ (\%) & \\
$\quad$ No & $3,804(68.29)$ \\
$\quad$ Yes & $1,766(31.71)$ \\
Drink, $n(\%)$ & \\
$\quad$ No &
\end{tabular}

subjects and $91.96 \%$ survived subjects were currently married, with a statistical difference $\left(\chi^{2}=101.341, p<\right.$ 0.001 ). Around $59.76 \%$ of the dead had no income, while $32.71 \%$ of the survived had no income, and the difference was statistically significant $\left(\chi^{2}=123.763, p<0.001\right)$; $38.29 \%$ dead subjects and $31.18 \%$ survived subjects reported a smoking history, respectively, and the smoking proportion was higher in the dead group than that in the survived group $\left(\chi^{2}=8.869, p=0.003\right)$. The median systolic blood pressure (SBP) of the dead and survived subjects was 150.50 (IQR: $132.00-169.00) \mathrm{mm} \mathrm{Hg}$ and 135.00 (IQR: 122.50-151.50) $\mathrm{mm} \mathrm{Hg}$, respectively, those dead had a higher SBP $(Z=10.411, p<0.001)$. The median body mass index (BMI) of the dead and survived subjects were $23.54(21.64-25.92) \mathrm{kg} / \mathrm{m}^{2}$ and $24.22(22.10-26.48)$ $\mathrm{kg} / \mathrm{m}^{2}$, respectively, and the dead had a lower BMI $(Z=$ $-3.302, p=0.001)$. Besides, compared with the survived subjects, the dead subjects had a larger spherical equivalent error $(Z=4.248, p<0.001)$, lower IOP $(Z=-4.912$, $p<0.001)$, smaller ACD $(Z=-9.186, p<0.001)$, larger length thickness $(Z=11.069, p<0.001)$, higher FBG level $(Z=5.650, p<0.001)$, higher total cholesterols level $(Z=$ $2.015, p=0.044)$, higher low-density lipoprotein level $(Z=2.024, p=0.043)$, and higher proportion of drug usage $\left(\chi^{2}=56.108, p<0.001\right)$. Compared with the survived subjects, the dead subjects were more likely to be with 
Table 2. Comparison of baseline information between survived and dead subjects

\begin{tabular}{|c|c|c|c|c|}
\hline Variables & Survived $(n=5,160)$ & Dead $(n=410)$ & Statistic & $p$ value \\
\hline Age & $52.00(42.00-58.00)$ & $67.00(58.00-72.00)$ & $Z=21.979$ & $<0.001$ \\
\hline \multicolumn{5}{|l|}{ Gender, $n(\%)$} \\
\hline Male & $2,318(44.92)$ & $255(62.20)$ & \multirow{2}{*}{$x^{2}=45.591$} & \multirow{2}{*}{$<0.001$} \\
\hline Female & $2,842(55.08)$ & $155(37.80)$ & & \\
\hline \multicolumn{5}{|l|}{ Education, $n(\%)$} \\
\hline Illiteracy & $738(14.30)$ & $132(32.20)$ & \multirow{3}{*}{$x^{2}=109.981$} & \multirow{3}{*}{$<0.001$} \\
\hline Primary school & $2,638(51.12)$ & $205(50.00)$ & & \\
\hline Middle school or higher & $1,784(34.57)$ & $73(17.80)$ & & \\
\hline \multicolumn{5}{|l|}{ Marriage, $n(\%)$} \\
\hline Single/divorced/widow & $415(8.04)$ & $94(22.93)$ & \multirow{2}{*}{$x^{2}=101.341$} & \multirow{2}{*}{$<0.001$} \\
\hline Married & $4,745(91.96)$ & $316(77.07)$ & & \\
\hline \multicolumn{5}{|l|}{ Income (RMB), $n$ (\%) } \\
\hline No income & $1,688(32.71)$ & $245(59.76)$ & \multirow{3}{*}{$x^{2}=123.763$} & \multirow{3}{*}{$<0.001$} \\
\hline $1-5,000$ & $2,305(44.67)$ & $118(28.78)$ & & \\
\hline$>5,000$ & $1,167(22.62)$ & $47(11.46)$ & & \\
\hline \multicolumn{5}{|l|}{ Smoke, $n$ (\%) } \\
\hline No & $3,551(68.82)$ & $253(61.71)$ & \multirow[b]{2}{*}{$x^{2}=8.869$} & \multirow[b]{2}{*}{0.003} \\
\hline Yes & $1,609(31.18)$ & $157(38.29)$ & & \\
\hline \multicolumn{5}{|l|}{ Drink, $n(\%)$} \\
\hline No & $4,059(78.66)$ & 326 (79.51) & \multirow[b]{2}{*}{$x^{2}=0.164$} & \multirow[b]{2}{*}{0.686} \\
\hline Yes & $1,101(21.34)$ & $84(20.49)$ & & \\
\hline $\mathrm{SBP}, \mathrm{mm} \mathrm{Hg}$ & $135.00(122.50-151.50)$ & $150.50(132.00-169.00)$ & $Z=10.411$ & $<0.001$ \\
\hline $\mathrm{DBP}, \mathrm{mm} \mathrm{Hg}$ & $77.00(69.00-85.00)$ & $77.50(68.00-87.50)$ & $Z=0.993$ & 0.321 \\
\hline $\mathrm{BMI}, \mathrm{kg} / \mathrm{m}^{2}$ & $24.22(22.10-26.48)$ & $23.54(21.64-25.92)$ & $Z=-3.302$ & 0.001 \\
\hline SER, D & $0.00(-0.50$ to 0.50$)$ & $0.25(-0.50$ to 1.13$)$ & $Z=4.248$ & $<0.001$ \\
\hline $\mathrm{IOP}, \mathrm{mm} \mathrm{Hg}$ & $15.00(13.00-17.00)$ & $14.25(12.50-16.00)$ & $Z=-4.912$ & $<0.001$ \\
\hline $\mathrm{ACD}, \mathrm{mm}$ & $2.73(2.44-3.01)$ & $2.52(2.21-2.79)$ & $Z=-9.186$ & $<0.001$ \\
\hline Length thickness, mm & $4.69(4.38-4.98)$ & $4.96(4.65-5.27)$ & $Z=11.069$ & $<0.001$ \\
\hline Axial length, $\mathrm{mm}$ & $22.80(22.28-23.29)$ & $22.74(22.24-23.31)$ & $Z=-0.893$ & 0.372 \\
\hline $\mathrm{FBG}, \mathrm{mmol} / \mathrm{L}$ & $5.52(5.15-5.99)$ & $5.73(5.23-6.58)$ & $Z=5.650$ & $<0.001$ \\
\hline \multicolumn{5}{|l|}{ Diabetes, $n$ (\%) } \\
\hline No & $4,892(94.81)$ & $358(87.32)$ & & \\
\hline Yes & $268(5.19)$ & $52(12.68)$ & $x^{2}=39.341$ & $<0.001$ \\
\hline $\mathrm{DR}, n(\%)$ & & & & \\
\hline No & $5,045(97.77)$ & 377 (91.95) & & \\
\hline Yes & $115(2.23)$ & $33(8.05)$ & $x^{2}=49.743$ & $<0.001$ \\
\hline Total cholesterols, $\mathrm{mmol} / \mathrm{L}$ & $4.50(3.94-5.15)$ & $4.54(4.03-5.31)$ & $Z=2.015$ & 0.044 \\
\hline Total triglycerides, $\mathrm{mmol} / \mathrm{L}$ & $1.25(0.89-1.82)$ & $1.20(0.87-1.70)$ & $Z=-1.183$ & 0.237 \\
\hline $\mathrm{HDL}, \mathrm{mmol} / \mathrm{L}$ & $1.25(1.09-1.43)$ & $1.28(1.07-1.47)$ & $Z=1.124$ & 0.261 \\
\hline $\mathrm{LDL}, \mathrm{mmol} / \mathrm{L}$ & $2.65(2.26-3.08)$ & $2.69(2.32-3.18)$ & $Z=2.024$ & 0.043 \\
\hline History of heart disease, $n$ (\% & & & & \\
\hline No & $4,910(95.16)$ & $369(90.00)$ & & \\
\hline Yes & $250(4.84)$ & $41(10.00)$ & $x^{2}=20.385$ & $<0.001$ \\
\hline Glaucoma, $n(\%)$ & & & & \\
\hline No & $5,095(98.74)$ & $392(95.61)$ & & \\
\hline Yes & $65(1.26)$ & $18(4.39)$ & $x^{2}=25.358$ & $<0.001$ \\
\hline $\mathrm{VI}, n(\%)$ & & & & \\
\hline No & $4,942(95.78)$ & $349(85.12)$ & & \\
\hline Yes & $218(4.22)$ & $61(14.88)$ & $X^{2}=90.596$ & $<0.001$ \\
\hline Cataract, $n(\%)$ & & & & \\
\hline No & $5,041(97.69)$ & $375(91.46)$ & & \\
\hline Yes & $119(2.31)$ & $35(8.54)$ & $x^{2}=54.843$ & $<0.001$ \\
\hline History of drug use, $n(\%)$ & & & & \\
\hline No & $3,742(72.52)$ & $226(55.12)$ & & \\
\hline Yes & $1,418(27.48)$ & $184(44.88)$ & $=56.108$ & $<0.001$ \\
\hline
\end{tabular}


Table 2 (continued)

\begin{tabular}{lllll}
\hline Variables & Survived $(n=5,160)$ & Dead $(n=410)$ & Statistic & $p$ value \\
\hline AMD, $n(\%)$ & & & & \\
$\quad$ No & $4,359(84.48)$ & $281(68.54)$ & $X^{2}=69.386$ & $<0.001$ \\
$\quad$ Yes & $801(15.52)$ & $129(31.46)$ & & \\
\hline
\end{tabular}

SBP, systolic blood pressure; DBP, diastolic blood pressure; BMI, body mass index; SER, spherical equivalent error; $I O P$, intraocular pressure; $A C D$, anterior chamber depth; FBG, fast blood glucose; HDL, high-density lipoprotein; LDL, low-density lipoprotein; AMD, age-related macular degeneration; DR, diabetic retinopathy.

Table 3. Risk factors of death using multivariable cox model

\begin{tabular}{|c|c|c|c|}
\hline Variables & Class & $\mathrm{HR}(95 \% \mathrm{Cl})$ & $p$ value \\
\hline Age & & $1.009(1.006,1.013)$ & $<0.001$ \\
\hline Gender & Male versus female & $1.117(1.051,1.188)$ & $<0.001$ \\
\hline \multirow[t]{3}{*}{ Education } & Middle school or higher & $0.789(0.715,0.870)$ & $<0.001$ \\
\hline & Primary school & $1.021(0.934,1.117)$ & 0.644 \\
\hline & Illiteracy & Reference & \\
\hline \multirow[t]{2}{*}{ Marriage } & Married & $1.026(0.924,1.138)$ & 0.632 \\
\hline & Single/divorced/widow & Reference & \\
\hline \multirow[t]{3}{*}{ Income (RMB) } & $>5,000$ & $0.491(0.391,0.616)$ & $<0.001$ \\
\hline & $1-5,000$ & $0.434(0.315,0.599)$ & $<0.001$ \\
\hline & No income & Reference & \\
\hline Smoke & Yes versus no & $0.964(0.921,1.009)$ & 0.112 \\
\hline $\mathrm{SBP}, \mathrm{mm} \mathrm{Hg}$ & & $1.020(1.016,1.024)$ & $<0.001$ \\
\hline $\mathrm{BMI}, \mathrm{kg} / \mathrm{m}^{2}$ & & $0.996(0.988,1.005)$ & 0.379 \\
\hline SER, D & & $1.001(0.984,1.018)$ & 0.928 \\
\hline IOP, $\mathrm{mm} \mathrm{Hg}$ & & $0.875(0.844,0.907)$ & $<0.001$ \\
\hline $\mathrm{ACD}, \mathrm{mm}$ & & $0.547(0.428,0.699)$ & $<0.001$ \\
\hline Length thickness, mm & & $0.990(0.927,1.057)$ & 0.765 \\
\hline $\mathrm{FBG}, \mathrm{mmol} / \mathrm{L}$ & & $1.132(1.087,1.179)$ & $<0.001$ \\
\hline Diabetes & Yes versus no & $1.082(0.898,1.305)$ & 0.406 \\
\hline $\mathrm{DR}$ & Yes versus no & $1.739(1.080,2.803)$ & 0.023 \\
\hline Total cholesterols, $\mathrm{mmol} / \mathrm{L}$ & & $0.963(0.920,1.009)$ & 0.111 \\
\hline $\mathrm{LDL}, \mathrm{mmol} / \mathrm{L}$ & & $1.150(0.982,1.347)$ & 0.084 \\
\hline History of heart disease & & $0.937(0.822,1.067)$ & 0.327 \\
\hline Glaucoma & Yes versus no & $0.943(0.733,1.211)$ & 0.644 \\
\hline VI & Yes versus no & $0.980(0.843,1.139)$ & 0.788 \\
\hline Cataract & Yes versus no & $0.945(0.781,1.144)$ & 0.564 \\
\hline History of drug use & Yes versus no & $0.992(0.928,1.060)$ & 0.808 \\
\hline AMD & Yes versus no & $1.061(0.992,1.135)$ & 0.084 \\
\hline
\end{tabular}

SBP, systolic blood pressure; BMI, body mass index; SER, spherical equivalent error; IOP, intraocular pressure; $A C D$, anterior chamber depth; FBG, fast blood glucose; HDL, high-density lipoprotein; LDL, low-density lipoprotein; $A M D$, age-related macular degeneration; $\mathrm{HR}$, hazard ratio; $\mathrm{VI}$, visual impairment; $\mathrm{Cl}$, confidence interval.

heart diseases $\left(\chi^{2}=20.385, p<0.001\right)$, VI $\left(\chi^{2}=90.596\right.$, $p<0.001)$, glaucoma $\left(\chi^{2}=25.358, p<0.001\right)$, cataract $\left(\chi^{2}=54.843, p<0.001\right)$, age-related macular degeneration $\left(\chi^{2}=69.386, p<0.001\right)$, diabetes $\left(\chi^{2}=39.341, p<0.001\right)$, and DR $\left(\chi^{2}=49.743, p<0.001\right)$.

Diabetic Retinopathy, Visual Impairment, and the Risk of Six-Year Death
Statistically significant variables in Table 2 were further included in the multivariable analysis using proportional hazards model (Table 3 ). After adjusting all relative confounders, DR was found to be a risk factor of the 6-year death, and the HR was 1.739 (95\% CI: 
$1.080,2.803)$, meaning that the risk of 6 -year death increased 0.739 times in DR patients compared with those who had no DR at baseline. Besides, age ( $\mathrm{HR}=1.009$, [95\% CI: 1.006, 1.013]), male gender ( $\mathrm{HR}=1.117$, [95\% CI: 1.051, 1.188]), SBP (HR = 1.020, [95\% CI: 1.016, $1.024])$, and FBG (HR $=1.132$, [95\% CI: 1.087, 1.179]) were also found to be risk factors of death. On the contrary, higher education was found to be a protective factor of death, and compared with the illiterate, subjects of middle school or higher education showed a 0.211 time decline on the risk of 6 -year death. Compared with subjects who had no income in the last year, death risk of subjects who earned 1-5,000 RBM and above 5,000 $\mathrm{RMB}$ in the last year decreased 0.566 times and 0.509 times, respectively. IOP $(\mathrm{OR}=0.875,[95 \% \mathrm{CI}: 0.844$, 0.907]) and ACD (OR $=0.547$, [95\% CI: 0.428, 0.699]) were also found to be protective factors of death.

We used another 5 different statistical models to test the robustness of our findings on the association between DR with the risk of 6-year death (online suppl. Table 1; see www.karger.com/doi/10.1159/000512667 for all online suppl. material). In model 1 , age was adjusted, and the HR was 3.036 (95\% CI: 2.125, 4.338). In model 2, age and gender were adjusted, and the HR was 3.313 (95\% CI: $2.317,4.737)$. In model 3 , age and diabetes were adjusted, and the HR was 2.622 (95\% CI: 1.490, 4.615). In model 4, age and FBG were adjusted, and the HR was 2.202 (95\% CI: $1.403,3.457)$. In model 5 , age, gender, diabetes, and FBG were adjusted, and the HR was 2.298 (95\% CI: 1.296, 4.076). All models showed a statistically significant association between DR and death.

\section{Discussion}

This population-based prospective cohort study showed that DR statistically increased the risk of 6-year death in a rural Chinese population of $\geq 30$ years. The risk of 6-year death of participants with DR at baseline increased as high as 1.739 (95\% CI: 1.080, 2.803) times compared to those without DR at baseline.

Our results agreed with the previous research conclusions $[3,5,6,13,14]$. Kramer and coworkers [14] conducted a meta-analysis involving 19,234 participants of diabetes from 20 studies to investigate the association of DR with all-cause mortality, and it turned out that in type 2 and type 1 diabetes patients, DR increased the risk of all-cause mortality by 1.34 times.

Population-based studies reported similar findings. The Singapore Malay Eye Study [5] followed 3,273 Malay adults aged $40-80$ years for 7.24 years, and 2 proportional hazard models were used to explore the association between DR and mortality. One model adjusted age and gender; another model adjusted age, gender, socioeconomic status, hypertension, smoking, BMI, and cardiovascular disease. Both models revealed a statistically significant association between DR and the increased all-cause mortality. In the Central Australian Ocular Health Study, Estevez and coworkers [6] recruited 1,347 indigenous Australians aged over 40 years at baseline; after a follow-up of 8.7 years, 1,257 were followed and the total mortality rate was $29.3 \%$. Results from a proportional hazard model showed that DR increased the risk of mortality; what's more, DR was the only condition that increased the likelihood of subsequent mortality.

In our study, we used 6 different models, with different confounders adjusted, to test the robustness of our findings. It turned out that all models revealed a statistically significant association between DR and the increased risk of 6-year death. Our findings further highlight the importance of prompt management of DR, which can be sight saving as well as life-saving. DR might be a specular sign for both ophthalmologists and physicians to pay particular emphasis on the management of diabetes.

Based on our study, the relationship between VI with the risk of 6-year death was not statistically significant. Previous studies assessing the relationship between VI and mortality reported mixed results. The Tanjong Pagar Study [15] followed 1,225 Chinese adults aged 4079 years living in Singapore for 6.8 years, and 126 died before follow-up. This study found that participants of lower presenting VA had a significantly higher mortality, concluded by a proportional hazards model where age, gender, hypertension, diabetes, smoking, heart attack, stroke, and income were adjusted. The Singapore Malay Eye Study [5] reported a similar finding. In another Chinese population-based cohort study [16], 5,057 subjects aged 50-96 years were included at baseline, and a total of 214 subjects (4.2\%) were dead after a 4 -year follow-up. In this study, VI was found to be significantly associated with the elevated mortality by a logistic regression model, where only age and gender were adjusted.

However, some studies reported nonsignificant findings on the association between VA and mortality $[17,18]$. In the Blue Mountains Eye Study [17], 3,663 participants aged $\geq 49$ years at baseline were followed-up for 11 years, and 1,051 participants (28.9\%) died. Then 
a proportional hazards model was used to explore the association between VI and mortality, confounders including age, sex, BMI, presence of hypertension, diabetes, current smoking, and baseline history of angina, acute myocardial infarction, and stroke were adjusted. The result showed that VI was not significantly associated with the 11-year mortality. Similarly, the Beijing Eye Study [18] recruited 4,439 subjects at baseline, and 2,695 subjects were followed-up 10 years later. The Beijing Eye Study used then used a multivariable logistic regression model to explore the association between VA and the 10year mortality; the adjusted confounders included age, gender, education, smoking, and DR, and the result was not statistically significant.

The inconsistency of studies assessing association between VI and mortality was much likely due to different studies adjusted for different confounders. DR was a very important influencing factor of death, but some studies failed to take it into consideration. What is more, some studies used only 1 statistical model, in which condition, the robustness of the results might not be reliable.

As expected, age, male gender, lower education, lower income, higher FBG, and higher blood pressure were found to be risk factors for mortality. A large number of studies have confirmed that women generally had longer life expectancy than men, although relatively little was known about the mechanisms underlying it $[19,20]$. Our research was in line with the results of previous studies that education was significantly associated with all-cause death $[21,22]$. The impact of education on mortality was understandable since education played an important role in people pursuing healthy lifestyle, such as following healthful diet, engaging in sport activities, and accessing health services et al. To our surprise, IOP and ACD were found to be protective factors of 6-year death in our study. However, due to the limited evidence on the 2 covariates, the reason was not clear.

The findings of the current study were strengthened by its prospective design, a relatively long follow-up period, large population with a limited amount of selection bias, a comprehensive set of covariates for adjustment in statistic models, standardized physical and, ocular examinations. However, there were some limitations in this study. It was likely that some unknown but significant confounders might be missed. Besides, as there was no formal death certificate for some villagers, we found it hard to get accurate information about the cause of death; thus, subgroups analysis was not applicable in this study.

Diabetic Retinopathy, Visual Impairment, and the Risk of Six-Year Death

\section{Conclusions}

DR significantly increased the risk of 6-year death in a rural Chinese population aged $\geq 30$ years old, while VI did not.

\section{Acknowledgements}

We appreciate the HES group as they made significant efforts for study design, field investigation, data entrance, data cleaning, and eye fundus reading.

\section{Statement of Ethics}

The study protocol of HES was reviewed and approved by the Ethical Committee of the Beijing Tongren Hospital (Ethical approval number TREC2006-22). The research was conducted according to the tenets of the Declaration of Helsinki. The informed consents from the subjects were obtained in this study.

\section{Conflict of Interest Statement}

The authors declare no conflict of interest.

\section{Funding Sources}

This study was supported by the grants from the Ministry of Science and Technology of China (No. 2007CB512201) and from the Key Technologies R\&D Program.

\section{Author Contributions}

Manuscript drafting was performed by Kai Cao and Bingsong Wang; manuscript revising was performed by David S. Friedman, Jie Hao, and Ye Zhang, Ailian $\mathrm{Hu}$; and study concept was created by Ningli Wang.

\section{Data Availability Statement}

Data are available upon reasonable request. 


\section{References}

1 Cheung N, Mitchell P, Wong TY. Diabetic retinopathy. Lancet. 2010;376:124-36.

2 Flaxman SR, Bourne RRA, Resnikoff S, Ackland $\mathrm{P}$, Braithwaite T, Cicinelli MV, et al. Global causes of blindness and distance vision impairment 1990-2020: a systematic review and meta-analysis. Lancet Glob Health. 2017; 5:e1221-34.

3 Garofolo M, Gualdani E, Giannarelli R, Aragona M, Campi F, Lucchesi D, et al. Microvascular complications burden (nephropathy, retinopathy and peripheral polyneuropathy) affects risk of major vascular events and allcause mortality in type 1 diabetes: a 10-year follow-up study. Cardiovasc Diabetol. 2019, 18:159.

4 Sabanayagam C, Chee ML, Banu R, Cheng CY, Lim SC, Tai ES, et al. Association of diabetic retinopathy and diabetic kidney disease with all-cause and cardiovascular mortality in a multiethnic asian population. JAMA Netw Open. 2019;2:e191540.

5 Siantar RG, Cheng CY, Gemmy Cheung CM, Lamoureux EL, Ong PG, Chow KY, et al. Impact of visual impairment and eye diseases on mortality: the Singapore Malay eye study (SiMES). Sci Rep. 2015;5:16304

6 Estevez J, Kaidonis G, Henderson T, Craig JE, Landers J. Association of disease-specific causes of visual impairment and 10-year mortality amongst indigenous Australians: the Central Australian ocular health study. Clin Exp Ophthalmol. 2018;46:18-24.

7 Cao K, Hao J, Zhang Y, Hu AL, Yang XH, Li $\mathrm{SZ}$, et al. Design, methodology, and preliminary results of the follow-up of a populationbased cohort study in rural area of northern
China: Handan eye study. Chin Med J. 2019; 132:2157-67.

8 Liang YB, Friedman DS, Wong TY, Wang FH, Duan XR, Yang XH, et al. Rationale, design, methodology, and baseline data of a population-based study in rural China: the Handan eye study. Ophthalmic Epidemiol. 2009;16: 115-27.

9 Pascolini D, Mariotti SP. Global estimates of visual impairment: 2010. Br J Ophthalmol. 2012;96:614-8.

10 Liang YB, Friedman DS, Zhou Q, Yang X, Sun LP, Guo LX, et al. Prevalence of primary open angle glaucoma in a rural adult Chinese population: the Handan eye study. Invest Ophthalmol Vis Sci. 2011;52:8250-7.

11 Duan XR, Liang YB, Wang NL, Wong TY, Sun LP, Yang XH, et al. Prevalence and associations of cataract in a rural Chinese adult population: the Handan eye study. Graefes Arch Clin Exp Ophthalmol. 2013;251:203-12.

12 Wang FH, Liang YB, Zhang F, Wang JJ, Wei WB, Tao QS, et al. Prevalence of diabetic retinopathy in rural China: the Handan eye study. Ophthalmology. 2009;116:461-7.

13 Soedamah-Muthu SS, Chaturvedi N, Witte DR, Stevens LK, Porta M, Fuller JH. Relationship between risk factors and mortality in type 1 diabetic patients in Europe: the EURODIAB prospective complications study (PCS). Diabetes Care. 2008;31:1360-6.

14 Kramer CK, Rodrigues TC, Canani LH, Gross JL, Azevedo MJ. Diabetic retinopathy predicts all-cause mortality and cardiovascular events in both type 1 and 2 diabetes: meta-analysis of observational studies. Diabetes Care. 2011;34 1238-44.
15 Foong AW, Fong CW, Wong TY, Saw SM, Heng D, Foster PJ. Visual acuity and mortality in a chinese population. The tanjong pagar study. Ophthalmology. 2008;115:802-7.

16 Li Z, Sun D, Liu P, Zhang L, Bai J, Cui H. Visual impairment and mortality in a rural adult population (the Southern Harbin eye study). Ophthalmic Epidemiol. 2011;18:54-60.

17 Cugati S, Cumming RG, Smith W, Burlutsky G, Mitchell P, Wang JJ. Visual impairment, age-related macular degeneration, cataract, and long-term mortality: the blue mountains eye study. Arch Ophthalmol. 2007;125:91724.

18 Wang YX, Zhang JS, You QS, Xu L, Jonas JB. Ocular diseases and 10-year mortality: the Beijing eye study 2001-2011. Acta Ophthalmol. 2014;92:e424-8.

19 Van Oyen H, Nusselder W, Jagger C, Kolip P, Cambois E, Robine JM. Gender differences in healthy life years within the EU: an exploration of the "health-survival" paradox. Int J Public Health. 2013;58:143-55.

20 Le Y, Ren J, Shen J, Li T, Zhang CF. The changing gender differences in life expectancy in Chinese cities 2005-2010. PLoS One. 2015; 10:e0123320.

21 Bonaccio M, Di Castelnuovo A, Costanzo S, Persichillo M, Donati MB, de Gaetano G, et al. Interaction between education and income on the risk of all-cause mortality: prospective results from the MOLI-SANI study. Int J Public Health. 2016;61:765-76.

22 Buckles K, Hagemann A, Malamud O, Morrill M, Wozniak A. The effect of college education on mortality. J Health Econ. 2016;50:99114 